\title{
ENTOMOLOGY
}

\section{Evaluation of light-traps with coloured glue-boards for sampling and control of the house fly Musca domestica L.}

\author{
M. Colacci, ${ }^{1}$ G. Spina, ${ }^{2}$ M. Boccamazzo, ${ }^{1}$ A. Sciarretta, ${ }^{1}$ P. Trematerra ${ }^{1}$ \\ ${ }^{1}$ Department of Agricultural, Environmental and Food Sciences, University of Molise, Campobasso, Italy; ${ }^{2}$ FASMI, \\ Cercemaggiore, Campobasso, Italy
}

\begin{abstract}
Results regarding the combination of light-traps and coloured glue-boards for the trap and control of the house fly, Musca domestica L. (Diptera: Muscidae), are reported. Monitoring was performed using as basic structure PRO 80S UV fluorescent fly traps in a confinement swine farm in the south of Italy. During the trials, neon traps with a combination of glue-boards (yellow vs black and yellow $v s$ white) and neon $v s$ LED traps with yellow glue-boards were evaluated. Results indicated that yellow and black glue-boards were equally attractive to flies, with no significant differences. Light-traps captured significantly more flies when a white glue-board was used rather than a yellow panel. The neon lamp attracted significantly more flies than the LED lamp. According to our results, light-traps with white panels have poten-
\end{abstract}

Correspondence: Marco Colacci, Department of Agricultural, Environmental and Food Sciences, University of Molise, via de Sanctis, 86100 Campobasso, Italy.

Tel.: +390874404656.

E-mail: marco.colacci@unimol.it.

Key words: Musca domestica, Light-traps, Coloured glue-boards, Livestock farm, Food industry.

Acknowledgments: We acknowledge Domenico Renzolla and Urbano Renzolla for assistance with experimentation.

Contributions: The authors contributed equally.

Conflict of interest: The authors declare no potential conflict of interest.

Funding: None.

Received for publication: 25 November 2020.

Accepted for publication: 8 January 2021.

${ }^{\circ}$ Copyright: the Author(s), 2020

Licensee PAGEPress, Italy

Journal of Entomological and Acarological Research 2020; $52: 9530$

doi:10.4081/jear:2020.9530

This article is distributed under the terms of the Creative Commons Attribution Noncommercial License (by-nc 4.0) which permits any noncommercial use, distribution, and reproduction in any medium, provided the original author(s) and source are credited. tial to be employed in Integrated Pest Management (IPM) programs for monitoring and controlling house flies in livestock farms and in food processing, reducing risks in dissemination of pathogens which have the potential to affect humans or animals.

\section{Introduction}

Light-traps are one of the most important tools used to monitor harmful populations of flies and other insects in food processing and storage areas (Hogsette, 2008; Bell, 2014; Trematerra, 2013; Lelieveld et al., 2014).

Many types of flies pose hygiene threats in the livestock farms and food industries in temperate countries, including house flies, blow flies, fruit flies, and drain flies. Infestations of each type of fly originate from different types of hygiene failures and increase the potential for transmission of faecal-oral pathogens. Flies carry over 100 different germs, including viruses, bacteria, fungi, and even the eggs of worms, more than 65 of which have the potential to affect humans or animals (Greenberg, 1965, 1973). As known house flies disseminate pathogens and diseases in three different ways: a fly's body surface, particularly its legs and proboscis, may be contaminated; pathogens can be regurgitated on to food via vomit drops; or pathogens may pass through the gut of the fly and be deposited in its faeces. Mechanical transfer of disease through either fly feeding, faeces, or saliva facilitates the spread of the most widely publicised risks to animal and human health: Escherichia coli, Salmonella and Shigella (Nassiri et al., 2015; Bahrndorff et al., 2017).

Flies also create the potential for bridges for disease transfer between stock in different buildings or on different farms, as well as from one batch of livestock to another as they pass through the same building, even despite thorough physical cleaning or biosecurity measures (Omalu et al., 2011; Phoku et al., 2016; Sarwar, 2016).

Light-traps can help reduce fly problems in livestock farms and in food processing plants when adequate attention is paid to removing potential breeding sites. Most insects that affect the food chain are attracted to light, however, optimal trap types and light characteristics vary greatly according to the pest-monitoring program (Hall et al., 2003; Trematerra \& Fleurat-Lessard, 2015; Bell et al., 2019). The assessment of light-traps is often an excellent place to begin the inspection of a facility (Bell, 2014). It is important to match the specific type of trap with the appropriate environmental conditions. Some factors affecting the choice of trap are the level of dust, the ambient temperature, insect population, and whether the trap is to be placed indoors or outdoors. In spring for 
example, the floors of unheated buildings are optimal for growth and development of food industry insects (i.e. Coleoptera, Diptera, Hymenoptera, Lepidoptera, etc). As temperature gradients change within buildings throughout the summer months, harsh conditions near the ceilings of facilities may hinder insect capture in monitoring programs (Hall et al., 2003; Campbell et al., 2012).

Due to the gradual introduction of numerous directives focusing on energy conservation and the use of lamps not containing dangerous substances, the light-trap market is currently advancing toward an important transformation. In Europe, the ErP Directive (EC) 244/2009 was implemented on September 1, 2018, stating that mercury vapour fluorescent lamps may no longer be manufactured or sold. Therefore, the use of LED technology could be important in the future, and studies aiming to optimise the performance of these kind of light-traps will be necessary (ErP Directive 244/2009).

In the present paper, we assess the feasibility of using a light-trap with a coloured glue-boards system to trap the house fly, Musca domestica L., by comparing a combination of glue-boards (yellow $v s$ black and yellow $v s$ white), and light sources (neon $v s$ LED).

\section{Materials and Methods}

The study was undertaken in a confinement swine farm in the south of Italy. All experiments were performed in a $320 \mathrm{~m}^{2}$ building that was internally subdivided by concrete walls approximately $1.5 \mathrm{~m}$ high. The building was selected because as it was the building most densely infested by the house fly, $M$. domestica. The stable contained a manger and various drinking troughs. The floor was made up of grids allowing excrement and sewage to be collected in an underground tank. The tank was emptied using mechanical pumps every two months.
The evaluation was conducted during 2019 throughout two trial series: coloured glue-board trials (divided in Test A and Test B) and light-trap trials.

The trials began on March 28 and ended on October 17. From August 2 through September 20, the farm was empty and no monitoring was performed; the underground tank remained empty during this period. The granular insecticidal bait Sugarkill Extra (acetamiprid $0.50 \mathrm{~g}+\mathrm{Z}-9$ tricosene $0.06 \mathrm{~g}$ ) (Copyr, Milano, Italy) was strategically placed in the stable throughout the entire experimental period.

Two light-trap, with similar basic structure, were used in our experiments. The first type of light trap was a fluorescent neon fly trap, model PRO 80S (Ekommerce, Atessa, Chieti, Italy) (Figure 1A). This trap was made of steel and had an open structure with dimensions $62.3 \mathrm{~cm}$ length, $29.5 \mathrm{~cm}$ height, and $11 \mathrm{~cm}$ depth. The trap was activated by two fluorescent MONSTER 40W lamps, Quantum T12 BL368 (Klight, Germany), radiation peak at $365 \mathrm{~nm}$ with viewing angle of $360^{\circ}$.

The second type of light-trap used was similar to the trap described above but used a $58 \mathrm{~cm}$ long LED strip instead of fluorescent lamps. The strip was composed of 72 LED pieces of two types (60 type 1 and 12 type 2 pieces), separated by $4.5 \mathrm{~mm}$. Every 5 pieces of type1, a type 2 was placed along the strip. The dimensions of both LED type pieces were $2.8 \times 3.5 \times 2 \mathrm{~mm}$, their power dissipation capacity was $0.5 \mathrm{~W}$, and their viewing angle was $90^{\circ}$. Type1 wavelength $(\lambda \mathrm{P})$ ranged from 365 to $375 \mathrm{~nm}$ and type $2 \lambda \mathrm{P}$ ranged between 395 and $405 \mathrm{~nm}$.

In all trial series, the light traps were placed along the wall of the stable, at a linear distance of at least $3 \mathrm{~m}$ from each other and approximately $1.5 \mathrm{~m}$ from the ground.

Three kinds of coloured glue-boards $(54.3 \times 30 \mathrm{~cm})$ were tested. The yellow TAK model glue-board and the black TAK model glue-board (Ekommerce, Atessa, Chieti, Italy) were a cardboard Kraft type with $2.5 \times 2.5 \mathrm{~cm}$ white grid mesh and a $47.6 \times 26 \mathrm{~cm}$
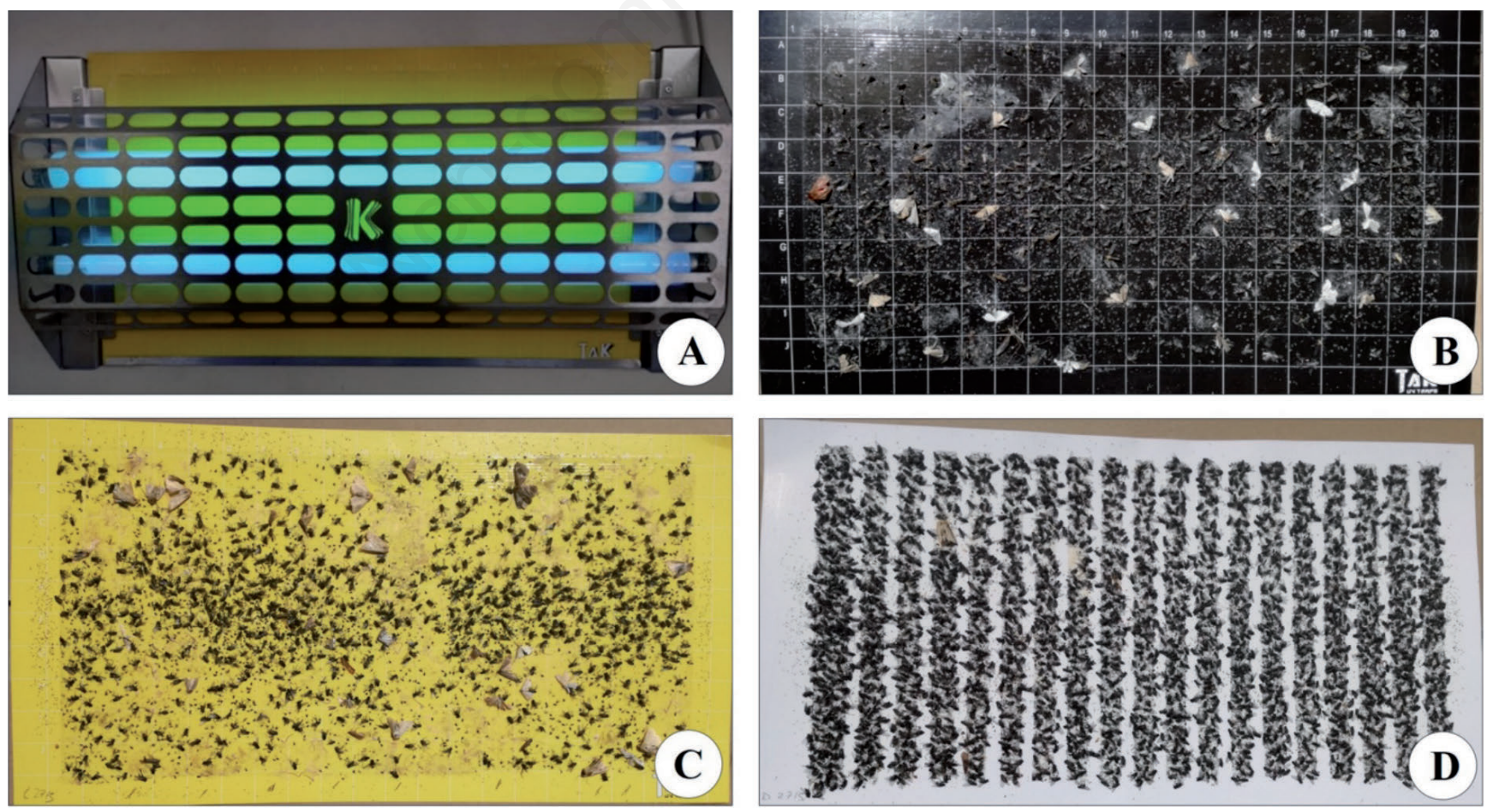

Figure 1. Fluorescent fly trap model PRO 80S (A) and glue-boards employed during the trials: black glue-board model TAK (B); yellow glue-board model TAK (C); white glue-board (with vertical glue strips) model FLUX (D). 
homogenous lamination of glue (Figures 1B and 1C). The white FLUX model glue-board (FASMI, Cercemaggiore, Campobasso, Italy) was an unpainted white cardboard board with nineteen laminated vertical strips of glue, $1.5 \mathrm{~cm}$ wide and spaced $1 \mathrm{~cm}$ from each other (Figure 1D).

\section{Experimental design}

\section{Coloured glue-board trials}

Test A was carried out in March and April of 2019. Four UV fluorescent neon fly traps were used and we compared two traps with yellow glue-boards $v s$ two traps with black glue-boards (Table 1). Test B was performed in the period between May and August 2019. Four UV fluorescent neon fly traps were used and we compared two traps with yellow glue-boards $v s$ two traps with white glue-boards. Test B was divided into two sub-periods (sub-period B1 and sub-period B2). Sub-period B1 was carried out between May and June, no additional insecticidal treatments were applied in building during this period. The sub-period B2 was executed between July and August, while cypermethrin (Cipex 10 E, Bleu Line, Forlì, Italy) treatments were being applied daily by the owner of the farm to the walls and floors of the premises, including the fly traps (Table 1).

\section{Light-trap trials}

The trials were performed between September and October of 2019. Two UV fluorescent neon traps were compared with two LED lamp traps. All traps had yellow model glue-boards (Table 1).

During the trials, traps were checked twice a week. During each check, the glue-boards were replaced with new ones and the traps were rotated from one position to the other in sequential order, thereby minimising bias due to trap positioning. Only M. domestica specimens trapped on the glue-board panels were quantified.

\section{Data analysis}

For experimental tests comparing yellow vs black panels (Test A of the coloured glue-board trials) and UV fluorescent neon $v s$ LED lamps (light-trap trials), the number of trapped $M$. domestica specimens were assessed using the Student's t-test for independent samples. For Test B of the coloured glue-board trials, data were analysed using two-way univariate ANOVA; the colour of the panel (yellow vs white panel) and the type of pest management employed (no insecticide treatment $v s$ insecticide treatment) were the independent variables.

In each trial, the trap checking was considered as a replicate of the experiment. Before the analyses were performed, data were $\ln (\mathrm{x}$
+ 1) transformed to normalise variance and standardise means. Statistical analyses were performed using SPSS statistical software.

\section{Results}

Light traps with coloured glue-boards captured a number of adults of fly. Across the experiment, a total of 77,513 M. domestica adults were trapped (7,974 adults in Test A and 46,329 in Test B of coloured glue-board trials; 23,210 during light-trap trials), seasonality had no impact on the direct comparisons.

\section{Coloured glue-board trials}

Results of Test A revealed that yellow panels and black panels were equally attractive to flies; no significant differences were observed when data were compared using a t-test $(t=1.271, \mathrm{df}=30$, $\mathrm{P}=0.214$ ) (Figure 2). Analysis of Test $\mathrm{B}$ data using ANOVA revealed that traps using white, rather than yellow, glue-boards captured significantly more flies $(\mathrm{F}=4.788 ; \mathrm{df}=1,76 ; \mathrm{P}=0.032)$. In the presence of insecticide treatments (sub-period B2), the number of flies caught was significantly lower compared to when treatments were absent (sub-period B1) $(\mathrm{F}=42.244$; $\mathrm{df}=1,76 ; \mathrm{P}<0.001)$. No interactions between panel colour and chemical treatment were observed $(\mathrm{F}=1.475 ; \mathrm{df}=1,76 ; \mathrm{P}=0.208)$. In the presence of insecticide treatments, the enhanced performance of the white panel over the yellow panel was reduced, although not in a significant way (Figure 3).

\section{Light-trap trials}

Results of light-trap trials revealed significant differences in the number of adult flies captured using the different types of lamp $(t=10.207, \mathrm{df}=30, \mathrm{P}<0.01)$. According to the data obtained, fluorescent neon lamps attracted a greater number of flies than the LED lamps (Figure 4).

\section{Discussion and Conclusions}

The problem of inducing flies to enter traps, rather than just arrive at traps, is one of the most difficult to solve in trap design. Many methods have been used to capture and assess synanthropic flies, however, there is little uniformity in these techniques used (Cohen et al., 1991; Kaufman et al., 2005; Geden, 2006; Hogsette, 2008).

Table 1. Fluorescent fly trap, model PRO 80S: details of the experimental trials conducted as well as the number of flies trapped.

\begin{tabular}{|c|c|c|c|c|}
\hline \multirow[t]{2}{*}{ Experimental periods } & \multicolumn{3}{|c|}{ Coloured glue-board trials } & \multirow{2}{*}{$\begin{array}{l}\text { Light-trap trials } \\
\text { (September-October) }\end{array}$} \\
\hline & $\begin{array}{c}\text { Test A } \\
\text { March-April }\end{array}$ & $\begin{array}{l}\text { sub-Test B1 } \\
\text { (May-June) }\end{array}$ & $\begin{array}{c}\text { sub-Test B2 } \\
\text { (July-August) }\end{array}$ & \\
\hline Type of light & $\begin{array}{l}\text { Two fluorescent } \\
\text { Neon lamps } \\
\text { MONSTER 40W, } \\
\text { Quantum T12 BL368 }\end{array}$ & $\begin{array}{c}\text { Two fluorescent } \\
\text { Neon lamps } \\
\text { MONSTER 40W, } \\
\text { Quantum T12 BL368 }\end{array}$ & $\begin{array}{l}\text { Two fluorescent } \\
\text { Neon lamps } \\
\text { MONSTER 40W, } \\
\text { Quantum T12 BL368 }\end{array}$ & $\begin{array}{l}\text { Two fluorescent } \\
\text { Neon lamps } \\
\text { MONSTER 40W, } \\
\text { Quantum T12 BL368 } \\
\text { vs LED strip }\end{array}$ \\
\hline Colour of glue-board & Yellow vs Black & Yellow vs White & Yellow vs White & Yellow \\
\hline Insecticide treatmentin building & No & No & Yes & No \\
\hline N. of $M$. domestica adults trapped & 7,974 & 36,771 & 9,558 & 23,210 \\
\hline
\end{tabular}


Muscid flies are known to be sensitive to differing wavelengths of light (Diclaro et al., 2012), and different colours of the spectrum may be used to improve trap catches (Pickens et al., 1994; Geden, 2006; Hanley et al., 2009; Gerry et al., 2011; Khan et al., 2013). Hall et al. (2003) demonstrated significant variations in the number of flies caught using different trap colours, both between species as well as within species. Although at least one study in the field has suggested that trap colour does not affect trap catches (Hanley et al., 2009), there are several studies suggesting the opposite (Hecht, 1970; Chapman et al., 1999; Geden, 2006; Diclaro et al., 2012).

Various studies have also been carried out in order to enhance understanding of light-trap function, as well as to improve the development and application of these traps in food processing plants (Fletcher \& Long, 1973; Hogsette, 2008; Shimoda \&
Honda, 2013). However, previous research has focused mainly on devices, and minimal data exists describing the effects of glueboard colour panels positioned inside UV light-traps.

It is known that visual stimuli have a decisive influence on the behaviour of arthropods. The ability to distinguish different wavelengths (colour vision) is the main function of a compound eye, while ocelli function to identify differences in light intensity (Hilbert, 1992; Mizunami, 1994). Adult house flies use reflected light from the environment during flight to search for food and identify refuge (Diclaro et al., 2012).

Some electroretinographic studies have shown that the eyes of $M$. domestica are sensitive to UV light between $340 \mathrm{~nm}$ and 370 $\mathrm{nm}$ and blue-green light between $480 \mathrm{~nm}$ and $510 \mathrm{~nm}$ (Goldsmith \& Fernandez, 1968; McCann \& Arnett, 1972).

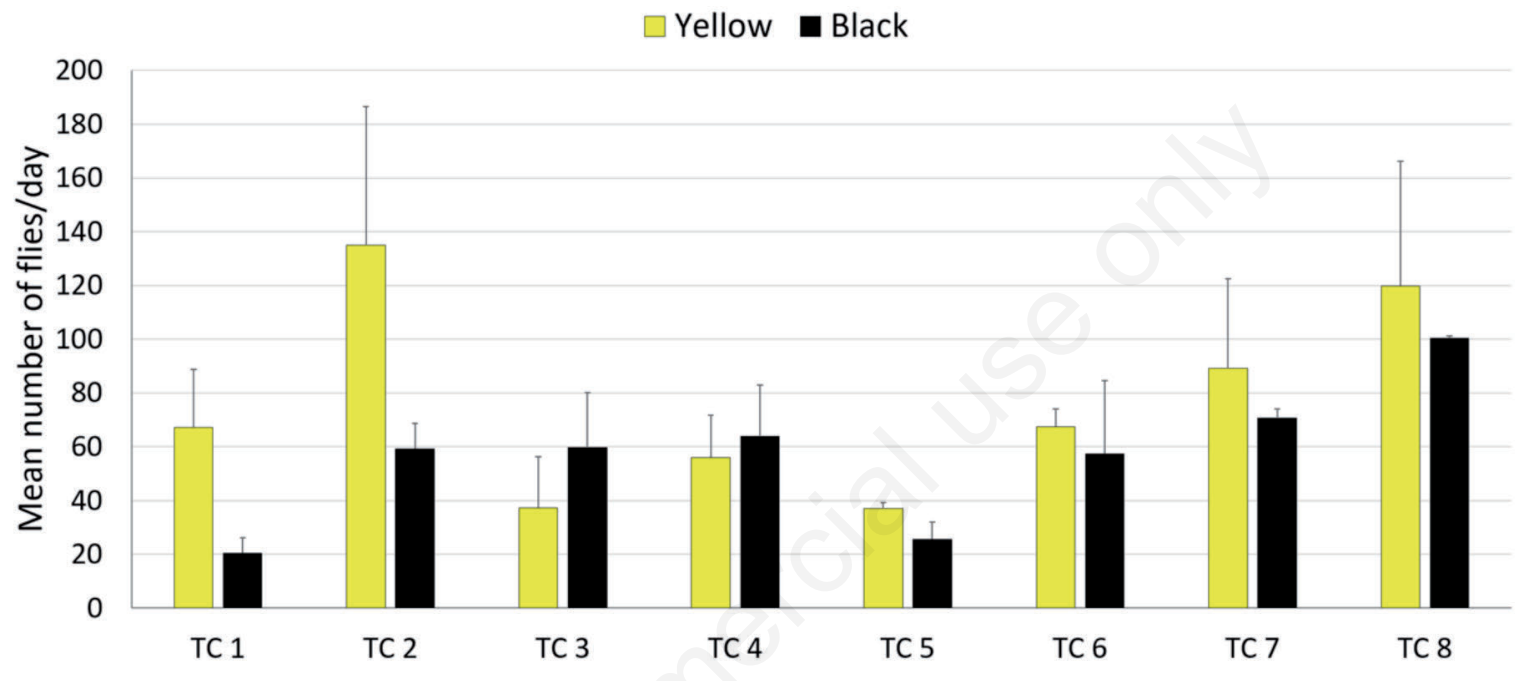

Figure 2. Coloured glue-board trials. Test A: mean number (+SE) of flies/day, yellow vs black glue-boards, captured in the neon traps (TC = trap checking).

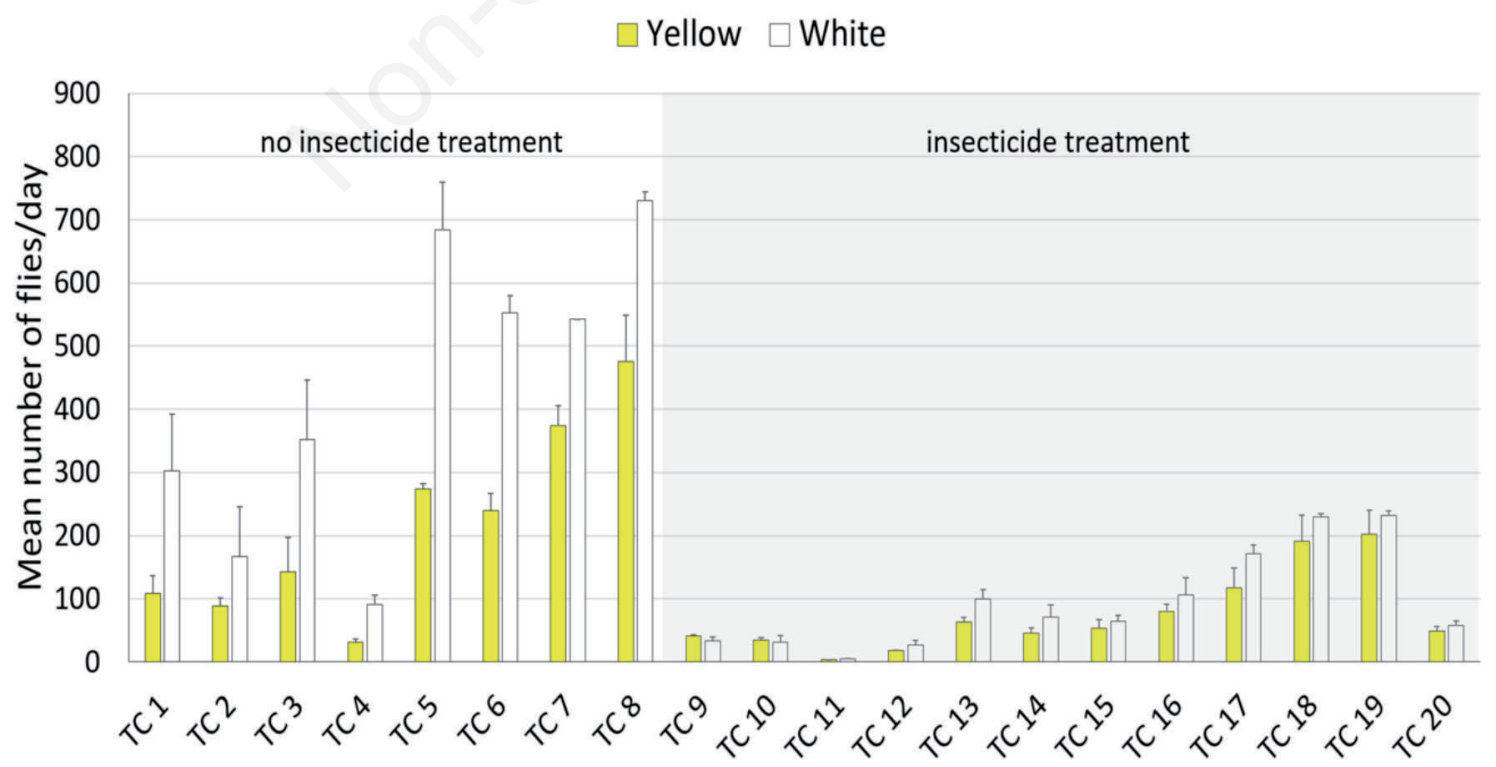

Figure 3. Coloured glue-board trials. Test B: mean number $(+\mathrm{SE})$ of flies/day, yellow vs white glue-boards, captured in the neon traps (TC = trap checking). 
Thimijan \& Pickens (1973) observed that the attractiveness of a light source tended to progressively decline from $390 \mathrm{~nm}$ to 630 $\mathrm{nm}$; additionally, no significant differences between males and females were observed. House flies, however, were mostly attracted to light reflected at $350 \mathrm{~nm}$ (Thimijan \& Pickens, 1973). Pickens \& Thimijan (1986) noted that the two elements with the largest influence on trap effectiveness were lamp brightness and the size of the UV emitting area.

The management of flies in and around structures of livestock farms and food industries can sometimes be difficult and no two situations are exactly alike, however, each control effort involves certain common steps. Sanitation, manure and breeding source removal, and exclusion are key steps in any fly management program (Trematerra, 2013; Trematerra \& Fleurat-Lessard, 2015). Integrated Pest Management (IPM) programs are particularly useful for nuisance fly control in intensive animal industries (dairy, beef, swine, and poultry), and some are specifically aimed at managing house flies.

To control flies in food chains (from field to fork), different schemes of pest control should be integrated in the production phases involving raw materials compared to the various processing departments leading to sale of the finalised food product, and best practices should be combined to minimise fly populations.

To successfully control flies, it is important that producers/operators implement an IPM control program that is best suited for the specific activity. Reliance on a single practice or pesticide product is not the best means to achieve effective and economical pest control. In general, a better approach combines routine sanitation with a variety of cultural, physical, biological, and pesticidal strategies, such as bait, residual sprays, space sprays, and larvicides in areas where flies are present.

In this context, to reduce pathogen contamination by $M$. domestica, physical barriers, for example, including exclusion methods such as nets and screens on windows and other openings to prevent flies from entering buildings, were determined to be universally useful. In addition to physical barriers, there is a need for improved long-term control, which can be accomplished by removing fly breeding grounds. General hygiene usually also requires improvement, and fly control is crucial for achieving this goal. Cleaning and fully removing dung from buildings deprives flies of the organic matter required to breed. Furthermore, flies will not breed in dry areas, therefore, simple measures such eliminating water leaks also significantly minimises fly populations.

With regards to food processing plants, light-traps have the potential for wide employment to monitor and control nuisance flies (while they may also catch beetles, wasps, and moths) in slaughterhouses, butchers, dairies, bakeries, restaurants, food processing plants, and supermarkets.

Often, light-traps are placed in order to help draw insects away from building entrances; therefore, the use of devices that are as efficient as possible is absolutely essential.

From a practical point of view, the following are some suggestions on how operators can increase the efficiency of light-traps. As $M$. domestica tend to fly within $1.5 \mathrm{~m}$ of the floor, light traps should be installed at approximately this height; traps hung from ceilings or installed high on walls do not catch as many flies. Install light traps so that they cannot be seen from outside of the building, either through windows or open doorways as flies and other insects could be attracted to the building, especially during night time hours. Install traps where they do not have to compete with sunlight or artificial lights; installation in dark areas can increase a light trap's effectiveness. In processing plants, install light traps at least $1.5 \mathrm{~m}$ away from food preparation surfaces as this attracts insects away from these areas.

According to our experimental findings in coloured glue-board trials, white panels with vertical glue strips trap a larger number of M. domestica specimens than yellow glue-boards, and in light-trap trials fluorescent neon lamps attract more flies than LED lamps. However, intraspecific diversity in insect behaviour between geographical regions, as reported by Hall et al. (2003), could have a significant impact on the effectiveness of systems for sampling and control of flies.

The mostly influential parameter in attracting house flies in our studies was the trap brightness, which increased as a result of enhanced light radiation from the high-gloss panel, due to the stripes not having glue [with SBS Brightness $\mathrm{C} / 2^{\circ}$ of $95 \%$ (ISO standard 2470-1:2019)]. In this regard it is important to point out

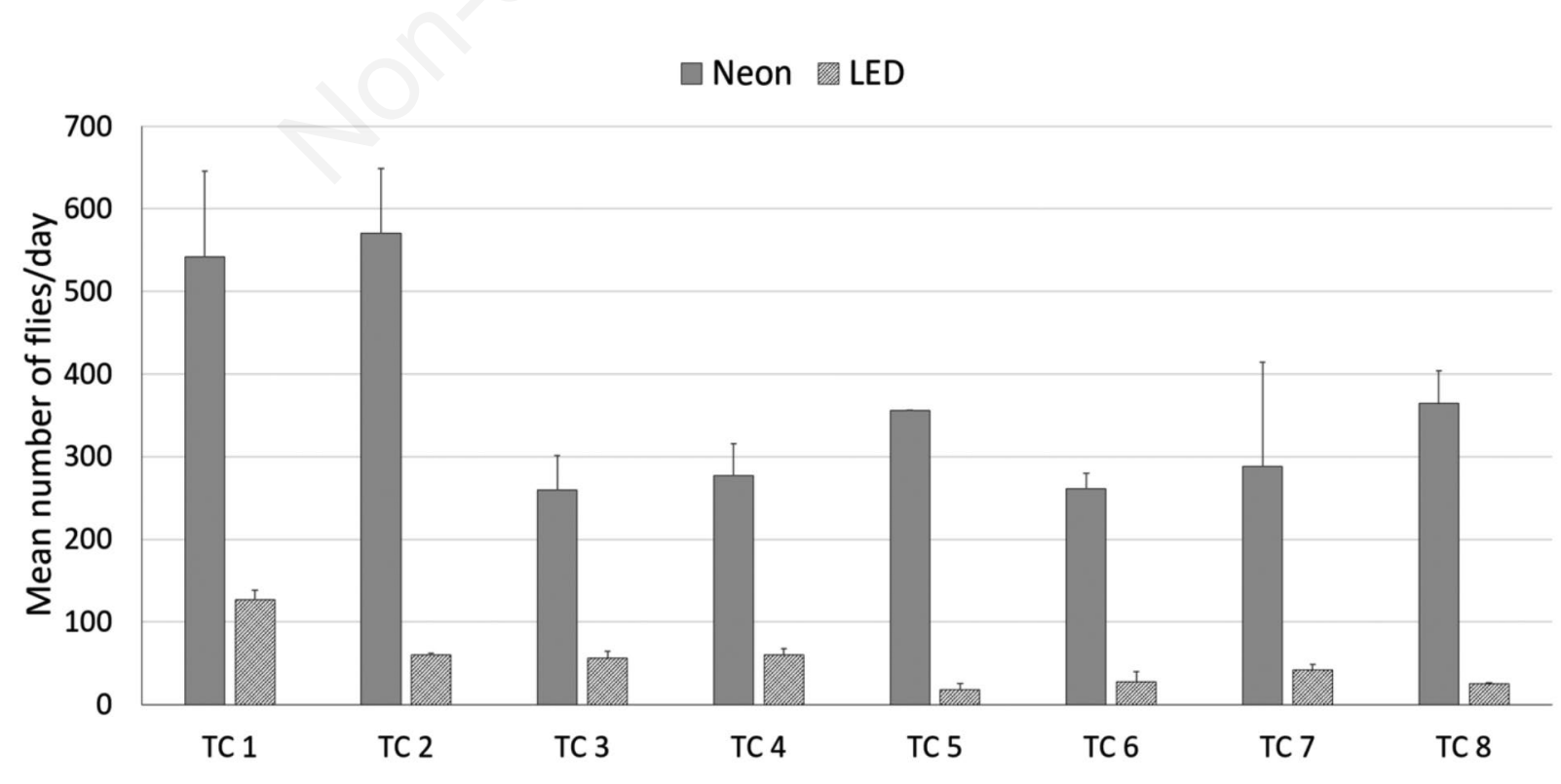

Figure 4. Light-trap trials. Mean number $(+\mathrm{SE})$ of flies/day captured in neon and LED traps with yellow glue-boards (TC = trap checking). 
that the lighting sources also varied in brightness, viewing angle and wavelength.

At the same time, it is interesting to note that treatments of the building with the insecticide cypermethrin during the B2 sub-period reduced the enhanced capture performance of the white striped adhesive panels compared to the yellow panels, likely as a result of the repellent effect from the presence of insecticide residue on the non-adhesive surface of the panel.

Either from a research or technical perspective, also in accordance with the indications reported in the ErP Directive (EC) $244 / 2009$, in the management of the house fly, M. domestica, further studies are needed to optimise LED trap performance by independently assessing the influence of lamp brightness, as well as glue strip size and orientation.

\section{References}

BAHRNDORFF S., DE JONGE N., SKOVGÅRD H., NIELSEN J.L., 2017 - Bacterial Communities Associated with Houseflies (Musca domestica L.) sampled within and between Farms. PLoS ONE 12: e0169753.

BELL M., 2014 - Pest control of stored food products: insects and mites. In: LELIEVELD H.L.M., HOLAH J., DAVIDNAPPER D., Hygiene in Food Processing. Principles and Practice. - Woodhead Publishing, Cambridge, UK: 494-538.

BELL M., IRISH S., SCHMIDT W.P., NAYAK S., CLASEN T., CAMERON M., 2019 - Comparing trap designs and methods for assessing density of synanthropic flies in Odisha, India. Parasite Vector 12: 2-10.

CAMPBELL J.F., PEREZ-MENDOZA J., WEIER J., 2012 - Insect Pest Management Decision in Food Processing Facilities. In: HAGSTRUM D.W., PHILLIPS T.W., CUPERUS G., Stored Product Protection. - Kansas State University, Manhattan, Kansas, USA: 219-232.

CHAPMAN J.W., KNAPP J.J., GOULSON D., 1999 - Visual responses of Musca domestica to pheromone impregnated targets in poultry units. - Med. Vet. Entomol. 13: 132-138.

COHEN D., GREEN M., BLOCK C., SLEPON R., AMBAR R., WASSERMAN S.S., LEVINE M.M., 1991 - Reduction of transmission of shigellosis by control of houseflies. - Lancet, 337: 993-997.

DICLARO J.W., COHNSTAEDT L.W., PEREIRA R.M., ALLAN S.A., KOEHLER P.G., 2012 - Behavioral and physiological response of Musca domestica to colored visual target. - J. Med. Entomol. 49: 94-100.

ERP DIRECTIVE (EC) 244/2009. Implementing Directive 2005/32/EC of the European Parliament and of the Council with regard to ecodesign requirements for non-directional household lamps. Available online: http://data.europa.eu/ eli/reg/2009/244/oj.

FLETCHER L.W., LONG J.S., 1973 - Evaluation of an electric grid light trap as a means of sampling populations of the cigarette beetle. - Tobacco Sci. 17: 37-39.

GEDEN C.J., 2006 - Visual targets for capture and management of house flies, Musca domestica L. - J. Vector Ecol. 31: 152-157.

GERRY A.C., HIGGINBOTHAM G.E., PERIERA L.N., LAM A., SHELTON C.R., 2011 - Evaluation of surveillance methods for monitoring house fly abundance and activity on large commercial dairy operations. - J. Econ. Entomol. 104: 1093-1102.

GOLDSMITH T.H., FERNANDEZ H.R., 1968 - The sensitivity of housefly photoreceptors in the mid-ultraviolet and the limits of the visible spectrum. - J. Exp. Biol. 49: 669-677.

GREENBERG B., 1965 - Flies and Diseases. - Sci. Am. 231: 92-99.

GREENBERG B., 1973 - Flies and Diseases: II. Biology and Disease Transmission. - Princeton University Press, Princeton, New Jersey, USA: 464 pp.

HALL M.J.R., HUTCHINSON R.A., FARKAS R., ADAMS
Z.J.O., WJATT N.P., 2003 - A comparison of Lucitrap and sticky targets for sampling the blowfly Lucilia sericata. - Med. Vet. Entomol. 17: 280-287.

HANLEY M.E., CRUICKSHANKS K.L., DUNN D., STEWARTJONES A., GOULSON D., 2009 - Luring houseflies (Musca domestica) to traps: do cuticular hydrocarbons and visual cues increase catch? - Med. Vet. Entomol. 23: 26-33.

HECHT O., 1970 - Light and color reactions of Musca domestica under different conditions. - Bull. Entomol. Soc. Am. 16: 94-98.

HILBERT D.R., 1992 - What is color vision. - Philos. Stud. 68: 351-370.

HOGSETTE J., 2008 - Ultraviolet Light Traps: Design Affects Attraction and Capture. In: ROBINSON W.H, BAJOMI D., Proceedings of the VI International Conference on Urban Pests. - OOK-Press Kft, Veszprém, Hungary: 193-196.

KAUFMAN P.E., RUTZ D.A., FRISCH S., 2005 - Large sticky traps for capturing house flies and stable flies in dairy calf greenhouse facilities. - J. Dairy Sci. 88: 176-181.

KHAN H.A., SHAD S.A., AKRAM W., 2013 - Combination of phagostimulant and visual lure as an effective tool in designing house fly toxic baits: a laboratory evaluation. - PLoS ONE 8: e77225.

LELIEVELD H.L.M., HOLAH J., DAVID-NAPPER D., 2014 Hygiene in Food Processing. Principles and Practice. Woodhead Publishing, Cambridge, UK: 640 pp.

MCCANN G.D., ARNETT D.W., 1972 - Spectral and polarization sensitivity of the Dipteran visual system. - J. Gen. Physiol. 59: 534-558.

MIZUNAMI M., 1994 - Functional diversity of neural organization in insect ocellar systems. Vision Res. 35: 443-452.

NASSIRI H., ZARRIN M., VEYS-BEHBAHANI R., FARAMARZI S., NASIRI A., 2015 - Isolation and identification of pathogenic filamentous fungi and yeasts from adult house fly (Diptera: Muscidae) captured from the hospital environments in Alivaz city, Southwestern Iran. - J. Med. Entomol. 52: 1351-1356.

OMALU I.C.J., AYANWALE V.A., AJALARURU A.B., MOHAMMED A.Z., BALA J., CHUKWUEMEKA V., 2011 Isolation of fungi and bacteria from housefly (Musca domesti$c a$ L.) larvae. - Int. J. Microb. 9: 1-4.

PHOKU J.Z., BARNARD T.G., POTGIETER N., DUTTON M.F., 2016 - Fungal dissemination by housefly (Musca domestica L.) and contamination of food commodities in rural areas of South Africa. - Int. J. Microb. 217: 177-181.

PICKENS L.G., THIMIJAN R.W., 1986 - Design parameters that affect the performance of UV-emitting traps in attracting house flies (Diptera: Muscidae). - J. Econ. Entomol. 79: 1003-1009.

PICKENS L., JAWOKSKI J., KOVAC B., MILLS G.D., 1994 Traps and baits for flies (Diptera) on Pacific Islands. - J. Med. Entomol. 31: 828-832.

SARWAR M., 2016 - Life History of House Fly Musca domestica Linnaeus (Diptera: Muscidae), its Involvement in Diseases Spread and Prevention of Vector. - Int. J. Res. Appl. Nat. Sci. 2: 31-42.

SHIMODA M., HONDA K.I., 2013 - Insect reactions to light and its applications to pest management. - Appl. Entomol. Zool. 48: 413-421.

THIMIJAN R.W., PICKENS L.G., 1973 - A method for predicting house fly attraction of electromagnetic radiant energy. - J. Econ. Entomol. 66: 95-100.

TREMATERRA P., 2013 - Aspects related to decision support tools and Integrated Pest Management in food chains. - Food Control 34: 733-742.

TREMATERRA P., FLEURAT-LESSARD F., 2015 - Food industry practices affecting pest management. - Stewart Postharvest Rev. 12: 1-7. 